\title{
An Overview of Coverage of BCG Vaccination and Its Determinants Based on Data from the Coverage Survey in Zhejiang Province
}

\author{
Yu Hu*, Yaping Chen, Hui Liang and Ying Wang \\ 1 Institute of Immunization and Prevention, Zhejiang Center for Disease Control and Prevention, \\ Hangzhou 310000, China; zjmyscyp@163.com (Y.C.); hliang@cdc.zj.cn (H.L.), ywang@cdc.zj.cn (Y.W.) \\ * Correspondence: yhu@cdc.zj.cn
}

Received: 10 April 2018; Accepted: 30 May 2018; Published: 1 June 2018

\begin{abstract}
To assess the Bacille Calmette-Guérin (BCG) vaccination coverage in Zhejiang province and to investigate predictors of the BCG vaccination, we used data from the 2017 Zhejiang provincial coverage survey. Demographic and immunization data on the selected children, their mothers, and their families were also collected by using a pre-tested questionnaire. BCG scars were verified among children who were available at the moment of survey. Coverage of BCG and other expanded program on immunization (EPI) vaccines scheduled before the first year of life was calculated. BCG coverage through the scar assessment and timeliness of BCG were also presented. Multivariate analyses of the predictors associated with the BCG vaccination and its timeliness were conducted separately. In total, 1393 children agreed to participate in the survey and presented the immunization cards. Of them, the coverage of BCG was $92.0 \%$ and $88.3 \%$ received the BCG within the first 28 days after birth. Besides this, 1282 out of the 1393 children were screened for the BCG scars and $97.1 \%$ of them had developed the scars. The multivariable logistic regression analyses indicated that hospital delivery, higher maternal education, a mother with no job, and a resident child were positively associated with the higher BCG vaccination coverage and its timely administrations. BCG coverage was optimal and it was administered in a timely manner. The majority of children vaccinated with BCG developed scars. Tailored interventions should be more greatly focused on and targeted to children with the risk factors identified in this study.
\end{abstract}

Keywords: BCG vaccine; coverage; determinants; expanded program on immunization; epidemiology

\section{Introduction}

Tuberculosis (TB) remains a global concern of public health as it is one of the leading causes of death by infectious agents worldwide and is responsible for an estimate of over one million deaths annually [1]. Although the efficacy of Bacille Calmette-Guérin (BCG) against pulmonary TB is controversial [2], it is the only available vaccine to prevent the most severe forms of childhood $\mathrm{TB}$, with a vaccine efficacy against $\mathrm{TB}$ meningitis and miliary $\mathrm{TB}$ of $73 \%$ and $77 \%$, respectively $[3,4]$. A recent study from Norway showed that BCG's protection was more cost-efficient than expected in a long-lasting situation [5]. Another report from Guinea-Bissau indicated that administering BCG at birth could reduce neonatal mortality by $48 \%$ among premature infants [6]. An additional importance of BCG vaccination is its proximity to the delivery and being an entry point to an expanded program on immunization (EPI) and other public health services [7].

The immunization policy of BCG issued by the Chinese center for disease and prevention includes three aspects: first, all newborns need to be administrated BCG at birth, except for a positive or suspicion of HIV infection; second, children three months to three years old without BCG vaccination 
should be screened by a purified protein derivative (PPD) test, and BCG should be given if the test result is negative; third, children aged $\geq 4$ years without $B C G$ vaccination need not be vaccinated. In China, there is only one licensed BCG vaccine (the D2 strain), which is derived from the strain Glaxo 1077 and manufactured by China Biotech Group Company (Beijing, China).

The development of a scar after BCG vaccination is a useful indicator of immune response [6,8], although there are other impact factors involved in the primary vaccination failure, such as poor cold chain management and inappropriate injection [3]. The widely applied methods for evaluating BCG coverage include the verification of the immunization record [9-13] and direct BCG scar observation $[14,15]$. Previous studies have indicated that female gender, a lower education level of parents, poor knowledge of immunization and vaccine-preventable diseases, a poor wealth index, and a great number of siblings were predictors of non-vaccination $[10,13,15]$.

China is a high TB burden country with the third highest number of TB cases reported annually worldwide $[16,17]$. To date, the control strategies of TB include improvement and enhancement of access to medical treatment and prevention through BCG vaccination. The Chinese EPI was launched in 1978 and a complete schedule before 12 months old includes one dose of BCG, three doses of poliovirus vaccine (PV), three doses of diphtheria-pertussis-tetanus vaccine (DPT), three doses of hepatitis B vaccine (Hep B), one dose of measles-rubella combined vaccine (MR), and one dose of Japanese encephalitis virus live attenuated vaccine (JEV). Vaccines included in the Chinese EPI are administered free of charge [18].

Administrative coverage estimates, which are calculated by using the report on vaccinations administered divided by the estimated target population, have remained over $99 \%$ in recent years in Zhejiang province. However, the administrative coverage is often unreliable due to incomplete or inaccurate immunization records, duplicate reporting, an outdated population census, and mistakes in compiling monthly summaries of vaccinations [19].

Thus, this study aimed to measure the BCG coverage using the data of the 2017 Zhejiang provincial coverage survey, through BCG records in immunization cards, and by BCG scar observation. Furthermore, we had another three secondary objectives: (1) to analyze the timeliness of BCG to assess whether it was administered in the right time period; (2) to compare the BCG coverage with other vaccine doses schedules before 12 months of age; and (3) to identify risk factors potentially associated with missed or untimely BCG vaccinations.

\section{Materials and Methods}

\subsection{Study Area}

Zhejiang province is on the East coast of China. It covers an area of $101,800 \mathrm{~km}^{2}$ and, with a population of 72 million (2016 census), is one of the most densely populated provinces in China. The annual population growth of Zhejiang province is around $10 \%$, with an estimated 726,511 births in 2016. Administratively, it is divided into 11 cities, 90 counties, and 1319 towns.

\subsection{Target Children}

A household-based cluster survey among children aged 24-35 months (born from 1 September 2014 to 31 July 2015) living in Zhejiang province was conducted in August 2017. The main purpose of this coverage survey was to evaluate the coverage of the 17 vaccine doses scheduled before 24 months of age. 


\subsection{Sample Size}

The sampling procedure of the 2017 Zhejiang provincial coverage survey was based on the immunization cluster survey recommended by the World Health Organization (WHO) [20]. The formula used to estimate the sample size was as follows:

$$
\mathrm{N}_{\min }=\operatorname{deff} \times \frac{z_{(1-\alpha / 2)}^{2} \times p \times(1-p)}{d^{2}}
$$

According to the survey protocol and to obtain the estimates of full coverage of the 17 doses scheduled before 24 months old at the city level with a two-tailed $\alpha$ error of $5 \%$, assuming a precision of 0.1 , and the expected full coverage ( $p$ ) at $80 \%$, and a design effect (deff) of 2 , the minimum sample size required for each city was 123 eligible children. For the convenience of practical operation, the final sample size was 126 for each city, which was divided into 6 clusters (towns) of 21 children in each cluster. As such, the sample size for the entire province was 1386.

\subsection{Survey Procedures}

First, six towns (clusters) for each city were selected from the list of towns (with the population size of each town) by city on the basis of the probability proportional to population size. Second, one community was randomly selected through a simple ballot from the list of all communities of each selected town. Third, the first household was selected randomly from the list of all households in the selected community by using a table of random numbers. Fourth, we selected the subsequent 20 households by turning to the right while exiting the household and visiting the adjacent households. Only one eligible child per household was randomly selected for the survey. Households were excluded if there were no eligible children or if they appeared vacant. Households in which somebody was living, but without any response, were re-scheduled for another visit. If we could not find 21 eligible children in the selected community, then we moved to the closest community in the same town and repeated the procedures above to survey the remaining children.

\subsection{Data Collection}

A pre-tested questionnaire, which was designed to take less than $15 \mathrm{~min}$, had been developed by the Zhejiang provincial center for disease control and prevention (ZJCDC). Mothers of the selected children were visited at home by trained interviewers. Immunization data were transcribed from immunization cards. Only written records were included in the survey and data analyses. Any child without written evidence of having received BCG vaccination or other EPI vaccinations from an immunization card was considered as not immunized and any child whose parents did not present the immunization card was also considered as not immunized. Demographic information and socio-economic characteristics of the selected children, their mothers, and their families were also collected. In order to assess BCG vaccination coverage through the presence of a scar, we checked the scars of all children enrolled in the survey if they were present at the moment of the interview.

\subsection{Measurements}

Vaccination coverage, of BCG and other EPI vaccines scheduled before 12 months of age, was defined as the proportion of children with a recorded vaccination administered in their immunization cards divided by children whose immunization card was available and assessed. Alternatively, to measure the coverage of BCG through the scar assessment, the vaccination coverage of BCG was calculated through the number of children presenting a BCG scar divided by the total number of children assessed for scarring. Timeliness of BCG was defined as a child receiving BCG before the first 28 days of life [11]. 


\subsection{Statistical Analysis}

We used STATA 11 (Stata Corp. 2009, Stata statistical software, college station, Lakeway, TX, USA) for data analyses. The description included qualitative variables and quantitative variables categorized according to the objective of the study. The demographic characteristics of surveyed children were described as absolute values and relative frequencies. The vaccination coverage estimates, including those based on verification of the immunization cards and observation of BCG scars, were calculated as a proportion with $95 \%$ confidence intervals (CI). The coverage rates of other EPI vaccinations scheduled before one year of age, including the third dose of PV (PV3), the third dose of Hep B (Hep B3), the third dose of DPT (DPT3), the first dose of JEV (JEV1), and MR, were also calculated as the reference.

The cumulative probability of being vaccinated for BCG was estimated at age $t$ through the inverse Kaplan-Meier survival function [21], the number of days of delay based on the maximum age at which the vaccination was recommended. Hence, the first day of delay of BCG was defined as the first day after the first 28 days of life. Children who had not received the BCG at the age of 28 days or unvaccinated children were considered as censored. The specific age at which a coverage of $90 \%$ was achieved was also evaluated.

Each socio-economic variable which seemed to be potentially associated with the administration of BCG and timeliness of BCG through verification of immunization cards was assessed by a $\chi^{2}$ test with odds ratios (OR) with a $95 \% \mathrm{CI}$ and $p$-values presented.

A stepwise procedure was carried out in order to build multivariate logistic regression models to evaluate the risk factors of missed BCG vaccination and the timeliness of BCG separately by using those variables with $p$-values $<0.1$ in the univariate analyses. The final models were fitted using backward selection with a cut-off level at $p<0.05$.

\subsection{Ethics Considerations}

This study was approved by the ethical review board of ZJCDC (T-037-S). All methods were carried out in accordance with relevant guidelines and regulations. Written informed consent was obtained from every caregiver once there was a decision to participate.

\section{Results}

\subsection{Demographic of the Surveyed Children}

In the 2017 Zhejiang provincial coverage survey, 1511 households with eligible children were visited, and there were 1406 (93.1\%) children and their parents who agreed to participate in the survey. Of them, 1393 children presented an immunization card to the field interviewer for transcription of the information on immunization and 1282 children were screened for BCG scars as they were at home during the interview. Of the children whose immunization cards were not available, eleven children declared the specific reasons (e.g., cannot find it/destroyed/lost it), while the other two had never received an immunization card before.

Of the children with immunization cards, $51.5 \%$ were male, $92.0 \%$ were delivered in hospital, $40.1 \%$ were migrants, $49.0 \%$ lived in rural areas, and $58.0 \%$ were within a distance of $5 \mathrm{~km}$ to the immunization clinics. Besides this, $65.6 \%$ of the surveyed households had one sibling, and $25.1 \%$ of the households had a monthly income of $>10,000$ CNY. Around $64.0 \%$ of the surveyed mothers were under 30 years of age, $79.4 \%$ of the surveyed mothers had a senior middle school background or above, $76.2 \%$ had jobs, and $74.0 \%$ had at least four visits to an antenatal clinic (ANC) (Table 1). 
Table 1. Summary distribution of the demographic characteristics of surveyed children with immunization cards $(\mathrm{N}=1393)$.

\begin{tabular}{|c|c|c|c|c|c|}
\hline Variables & $n$ & $\%$ & Variables & $n$ & $\%$ \\
\hline Sex & & & Residence & & \\
\hline Male & 718 & 51.5 & Urban & 710 & 51.0 \\
\hline Female & 675 & 48.5 & Rural & 683 & 49.0 \\
\hline Number of siblings & & & Immigration status & & \\
\hline 1 & 914 & 65.6 & Resident & 835 & 59.9 \\
\hline 2 & 363 & 26.1 & Migrant & 558 & 40.1 \\
\hline$\geq 3$ & 116 & 8.3 & Antenatal clinic (ANC) visits & & \\
\hline Place of delivery & & & none & 55 & 3.9 \\
\hline Hospital & 1281 & 92.0 & $1-3$ & 307 & 22.0 \\
\hline Home & 112 & 8.0 & $\geq 4$ & 1031 & 74.0 \\
\hline Age of mother (years) & & & Distance to immunization clinic & & \\
\hline$<30$ & 892 & 64.0 & $<5 \mathrm{~km}$ & 585 & 42.0 \\
\hline$\geq 30$ & 501 & 36.0 & $\geq 5 \mathrm{~km}$ & 808 & 58.0 \\
\hline Maternal education level & & & Monthly household income per capita & & \\
\hline$<$ senior middle school & 287 & 20.6 & $<5000 \mathrm{CNY}$ & 272 & 19.5 \\
\hline$\geq$ senior middle school & 1106 & 79.4 & $5000-10,000 \mathrm{CNY}$ & 772 & 55.4 \\
\hline Maternal employment status & & & $>10,000 \mathrm{CNY}$ & 349 & 25.1 \\
\hline Home fulltime & 331 & 23.8 & & & \\
\hline Employed & 1062 & 76.2 & & & \\
\hline
\end{tabular}

\subsection{Vaccination Coverage and the Scar Evaluation}

Table 2 shows that the coverage of BCG was $92.0 \%$ (95\% CI: 90.6-93.5\%). The coverage of PV3, DPT3, Hep B3, JEV1, and MR was 91.3\% (95\% CI: 89.8-92.8\%), 90.5\% (95\% CI: 88.9-92.2\%), 93.5\% (95\% CI: 92.2-94.8\%), 91.1\% (95\% CI: 89.3-92.9\%), and 90.7\% (95\% CI: 89.0-92.4\%), respectively. From the 1282 children observed for the presence of a BCG-compatible scar, all of them had immunization cards and BCG vaccination records and 1245 children (97.1\%) had developed the scars.

Table 2. Vaccination coverage among the surveyed children with immunization cards $(\mathrm{N}=1393)$.

\begin{tabular}{cccc}
\hline Vaccination Dose & Number of Children Immunized & $\mathbf{\%}$ & $\mathbf{9 5 \%} \mathbf{C I}$ \\
\hline BCG & 1282 & 92.0 & $90.6-93.5$ \\
PV3 & 1272 & 91.3 & $89.8-92.8$ \\
DPT3 & 1261 & 90.5 & $88.9-92.2$ \\
Hep B3 & 1303 & 93.5 & $92.2-94.8$ \\
JEV1 & 1269 & 91.1 & $89.3-92.9$ \\
MR & 1263 & 90.7 & $89.0-92.4$ \\
\hline
\end{tabular}

BCG, Bacille Calmette-Guérin; PV, poliovirus vaccine; DPT, diphtheria-pertussis-tetanus vaccine; Hep B, hepatitis B; JEV, Japanese encephalitis virus live attenuated vaccine; MR, measles-rubella combined vaccine; CI, confidence interval.

The multivariable logistic regression analyses revealed that the child born in hospital, higher maternal education, mother with no job, and resident child predictors were positively associated with a higher likelihood of being vaccinated with BCG (Table 3). 
Table 3. Univariate and multivariate analyses of the predictors associated with the BCG vaccination.

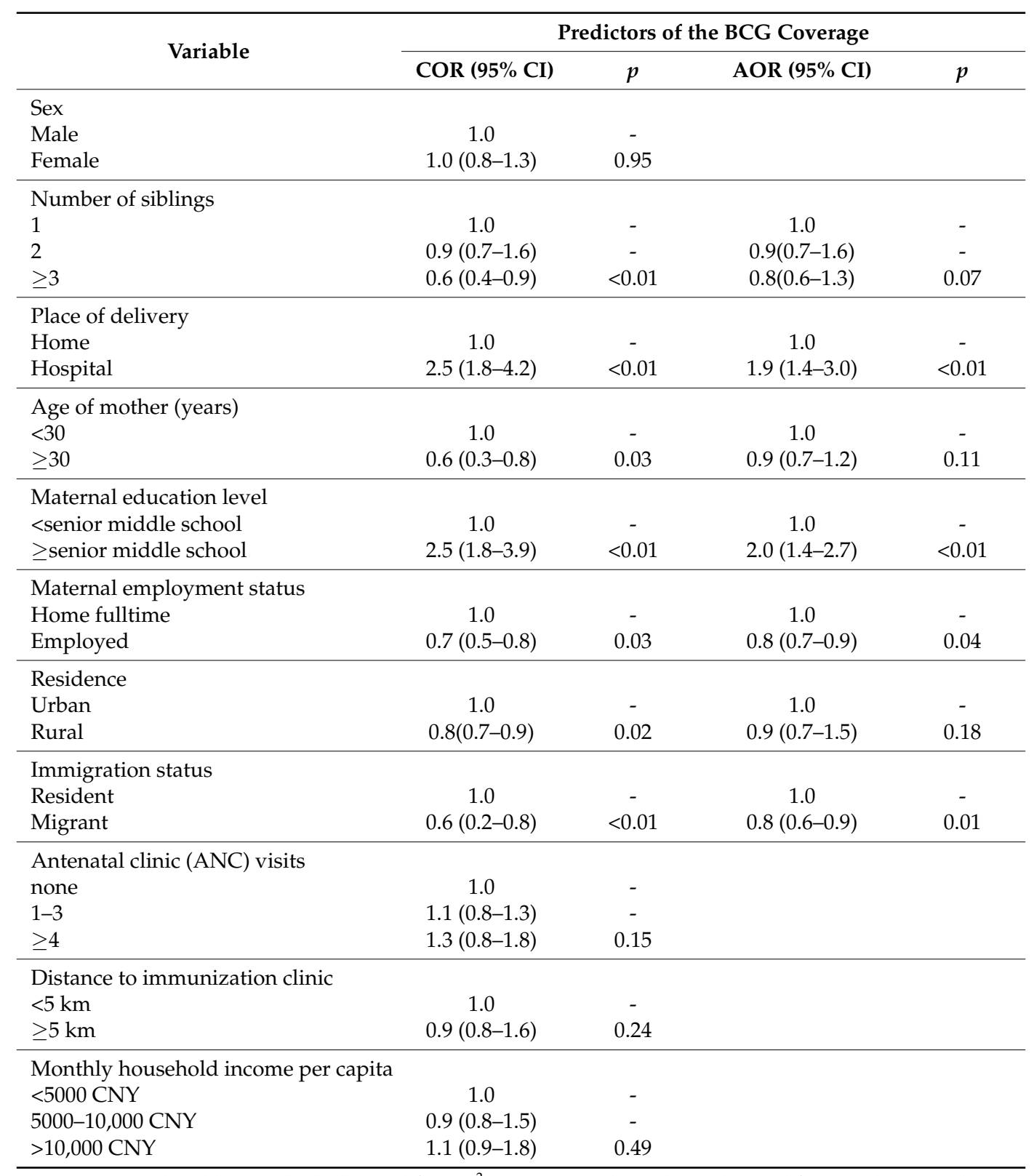

Note: COR: crude odds ratio (OR) obtained from $\chi^{2}$ test; AOR: Adjusted OR obtained from multivariate logistic regression analysis.

\subsection{Timeliness of $B C G$}

Figure 1 represents the distribution of BCG vaccination administrated to children from the day of birth to 28 days old. The result indicated that $88.3 \%$ (1230) of the surveyed children received a BCG vaccination within the first 28 days of life. 


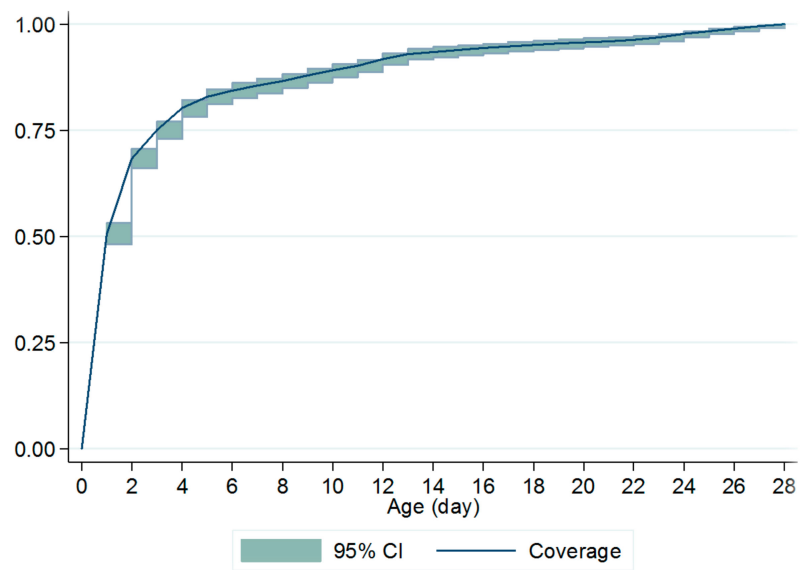

Figure 1. Inverse Kaplan-Meier curves showing the proportion of children immunized with BCG among the surveyed children with immunization cards $(\mathrm{N}=1393)$.

The multivariable logistic regression analyses revealed that the less siblings in a family, child born in hospital, higher maternal education, mother with no job, and resident child predictors were positively associated with a higher timeliness of BCG vaccination (Table 4).

Table 4. Univariate and multivariate analyses of the predictors associated with the timeliness of BCG vaccination

\begin{tabular}{|c|c|c|c|c|}
\hline \multirow{2}{*}{ Variable } & \multicolumn{4}{|c|}{ Predictors of the Timeliness of BCG } \\
\hline & COR $(95 \% \mathrm{CI})$ & $p$ & AOR $(95 \% \mathrm{CI})$ & $p$ \\
\hline \multicolumn{5}{|l|}{ Sex } \\
\hline Male & 1.0 & & & \\
\hline Female & $1.1(0.8-1.3)$ & 0.71 & & \\
\hline \multicolumn{5}{|l|}{ Number of siblings } \\
\hline 1 & 1.0 & - & 1.0 & - \\
\hline 2 & $0.8(0.6-0.9)$ & - & $0.9(0.7-1.5)$ & - \\
\hline$\geq 3$ & $0.6(0.3-0.8)$ & $<0.01$ & $0.7(0.5-0.9)$ & 0.01 \\
\hline \multicolumn{5}{|l|}{ Place of delivery } \\
\hline Home & 1.0 & - & 1.0 & - \\
\hline Hospital & $3.0(1.9-4.6)$ & $<0.01$ & $1.9(1.3-2.7)$ & 0.03 \\
\hline \multicolumn{5}{|l|}{ Age of mother (years) } \\
\hline$<30$ & 1.0 & - & 1.0 & - \\
\hline$\geq 30$ & $0.8(0.6-0.9)$ & 0.03 & $1.0(0.9-1.1)$ & 0.20 \\
\hline \multicolumn{5}{|l|}{ Maternal education level } \\
\hline$<$ senior middle school & 1.0 & - & 1.0 & - \\
\hline$\geq$ senior middle school & $4.1(2.7-7.0)$ & $<0.01$ & $2.8(1.9-4.5)$ & $<0.01$ \\
\hline \multicolumn{5}{|l|}{ Maternal employment status } \\
\hline Home fulltime & 1.0 & - & 1.0 & - \\
\hline Employed & $0.7(0.5-0.8)$ & $<0.01$ & $0.8(0.6-0.9)$ & 0.04 \\
\hline \multicolumn{5}{|l|}{ Residence } \\
\hline Urban & 1.0 & - & & \\
\hline Rural & $1.1(0.9-1.3)$ & 0.27 & & \\
\hline \multicolumn{5}{|l|}{ Immigration status } \\
\hline Resident & 1.0 & - & 1.0 & - \\
\hline Migrant & $0.5(0.3-0.7)$ & $<0.01$ & $0.7(0.4-0.8)$ & $<0.01$ \\
\hline \multicolumn{5}{|l|}{ Antenatal clinic (ANC) visits } \\
\hline none & 1.0 & - & & \\
\hline $1-3$ & $1.0(0.8-1.4)$ & - & & \\
\hline$\geq 4$ & $1.4(0.8-2.1)$ & 0.11 & & \\
\hline \multicolumn{5}{|l|}{ Distance to immunization clinic } \\
\hline$<5 \mathrm{~km}$ & 1.0 & - & 1.0 & - \\
\hline$\geq 5 \mathrm{~km}$ & $0.7(0.5-0.8)$ & 0.03 & $0.9(0.8-1.7)$ & 0.31 \\
\hline \multicolumn{5}{|l|}{ Monthly household income per capita } \\
\hline$<5000$ CNY & 1.0 & - & & \\
\hline $5000-10,000 \mathrm{CNY}$ & $1.1(0.8-1.9)$ & - & & \\
\hline$>10,000 \mathrm{CNY}$ & $1.3(0.9-2.0)$ & 0.19 & & \\
\hline
\end{tabular}

Note: COR: crude OR obtained from $\chi^{2}$ test; AOR: Adjusted OR obtained from multivariate logistic regression analysis. 


\section{Discussion}

This study provided a population estimate of BCG vaccination by using the most recent vaccination coverage survey data. It showed that the coverage of BCG was very high in children 24-35 months old, surpassing the coverage goal set by the Chinese center for disease control and prevention (CDC). However, the coverage of BCG in this study was a little lower than that derived from the Zhejiang provincial immunization information system (ZJIIS), which was $98.7 \%$ in children 24 months old [22]. It is known that the estimate from the ZJIIS was based on children who had already registered in the ZJIIS and children not registered in the ZJIIS would be more likely to be missed by routine immunization. Thus, the vaccination coverage derived from the ZJIIS might be overestimated when compared with the coverage from the field survey.

In this study, we found that the coverage of vaccine doses scheduled before the first birthday was over $90 \%$. We thought that the enhancement of routine immunization program strategies (such as sending text messages as reminders to have administered all vaccines due) that had been conducted in every community since 2011 could potentially affect the vaccination-seeking behavior of children's caregivers. However, there might be a selection bias since 13 children failed to present immunization cards. Although most of them had received immunization cards previously, if those who did not present the card had lower coverage, our estimates might represent a slight overestimation of the true coverage. Compared with other vaccinations scheduled before 12 months of age, the coverage of BCG was higher than that of the other vaccine doses studied except for HBV3. Administration of Hep B at birth is required for any registered maternity hospital in China, while the administration of BCG at birth is recommended but not mandatory [23]. As such, children born in maternity hospitals would be more likely to start a Hep B series or obtain a BCG vaccination and the coverage of these two vaccines would be higher than that of other vaccines. On the other hand, the coverage of BCG might be lower than that for Hep B as some children who did not receive the BCG vaccine in a timely manner would be exempted from BCG vaccination as their PPD readings were positive or they were over 4 years of age.

According to the immunization cards observed, very few children vaccinated with BCG failed to develop the scar. Our findings were consistent with similar studies in other countries, ranging from $1 \%$ to $20 \%$ [24-27]. Observer bias could have occurred as field investigators were not blind to the records from immunization cards. Recent studies showing beneficial effects associated with scars, such as a decreased mortality in children with scars, has opened an argument on re-vaccinating children who failed to develop a scar after the first BCG vaccination $[3,6]$. Some have also suggested that the BCG scar should be an indicator to monitor the performance of the immunization program [25].

The timing of vaccination is critical for obtaining timely protection, but also for being an indicator of non-adherence. We considered a BCG vaccination to be timely if it occurred within the first 28 days of life, which is the criterion recommended by the WHO. In this study, the proportion of delayed BCG vaccination was $11.7 \%$, which was lower than the $33 \%$ found in another report from Tanzania [12]. However, definitions of delayed BCG vaccination differ from place to place. For example, some African countries considered it to occur after eight weeks after birth, thus comparisons with other studies should be made cautiously [11,13].

In this study, we found four determinants associated with BCG vaccination and its timely administration. First, as we mentioned before, a proportion of maternity hospitals provided a BCG vaccination together with the first dose of Hep B, which is mandatory for all maternity hospitals to give every newborn after birth. As such, children delivered at hospitals might have an increased likelihood to be vaccinated in a timely manner. Moreover, mothers who gave birth at hospital might be closer to the public health service and would have a better utilization of an immunization service [18]. Second, a higher maternal education level could assist mothers to communicate with health workers efficiently and have a positive impact on vaccination through a better understanding and acceptance of immunization knowledge. Previous reports have shown that a child whose mother has a lower education level is less likely to receive full immunizations [28,29]. Besides this, a mother 
with a higher education background would have a better awareness and capacity to take advantage of an immunization service [30-33]. Third, we assumed that mothers with jobs had less time to spare for childhood immunization as it might not be one of the priorities amidst other competing events to bring healthy children to obtain vaccinations. At the same time, previous studies have demonstrated that those mothers were less aware of the information on vaccination [34-36]. Fourth, we found that the patterns of utilization of a vaccination service of migrant children were not similar to those of resident children. Although the exact reasons need to be explored in future research, we attributed a missed or delayed BCG vaccination to the vulnerability of migrant people in a new sociocultural environment, the demand for the service, negative immunization experiences, and the capacity of providers [37-39]. Furthermore, there was another determinant only associated with the timeliness of BCG vaccination. Children with more siblings were found to have an increased probability to receive a BCG vaccination in an untimely manner. We assumed that families incurred a greater cost and required more resources to support more children, which might adversely affect health service utilization. Another study suggested that parental attention would be diverted by other children and the motivation for parents to prioritize immunization amidst competing demands for time was limited since the benefits of vaccination sometimes might not be immediately apparent [40].

This study had several limitations. First, selection bias could occur in evaluating the BCG coverage through scar reading since only children who were present at the moment of the interview were included. Secondly, although most of the children who could not present an immunization card stated that they had received one previously, these children might live in families with more difficulties in accessing the health system or not be able to have a proper follow up of their vaccination status; thus, our vaccination coverage could be overestimating the real one. Last, as this study focused only on one birth cohort, the results might be subjected to a cohort effect/bias if there was unusually good coverage in that cohort due to some unknown or uncertain reasons. We would like to continuously monitor the BCG coverage trends for a long period of time and explore its risk factors.

\section{Conclusions}

This study showed an optimal vaccination coverage of BCG. The vast majority of BCG vaccines were given within the first 28 days after birth. Scar development occurred in almost all infants. Several risk factors were identified for the lack of BCG vaccination or delayed BCG administration. Tailored interventions should be more greatly focused on and targeted to children not delivered at hospital, children whose mothers are less educated or have a fixed job, migrant children, and children with more siblings.

Author Contributions: Y.H. conceived and designed the experiments; Y.H. and Y.C. performed the experiments; Y.H. and Y.W. analyzed the data; H.L. and Y.W. contributed reagents/materials/analysis tools; and Y.H. wrote the paper.

Funding: This research received no external funding.

Acknowledgments: Great acknowledgement goes to the immunization staff from 11 CDCs at the city level for their investigation and data collection.

Conflicts of Interest: The authors declare no conflict of interest.

\section{References}

1. Burki, T.K. The global cost of tuberculosis. The lancet. Respir. Med. 2018, 6, 13.

2. Van-Dunem, J.C.V.D.; Rodrigues, L.C.; Alencar, L.C.; Militao-Albuquerque, M.F.P.; Ximenes, R.A. Effectiveness of the first dose of BCG against tuberculosis among HIV-infected, predominantly immunodeficient children. BioMed Res. Intern. 2015, 2015, 275029. [CrossRef] [PubMed]

3. Dhanawade, S.S.; Kumbhar, S.G.; Gore, A.D.; Patil, V.N. Scar formation and tuberculin conversion following BCG vaccination in infants: A prospective cohort study. J. Fam. Med. Prim. Care 2015, 4, 384-387. [CrossRef] [PubMed] 
4. Abubakar, I.; Pimpin, L.; Ariti, C.; Beynon, R.; Mangtani, P.; Sterne, J.A.; Fine, P.E.; Smith, P.G.; Lipman, M.; Elliman, D.; et al. Systematic review and meta-analysis of the current evidence on the duration of protection by Bacillus Calmette-Guerin vaccination against tuberculosis. Health Technol. Assess. 2013, 17, 1-372. [CrossRef] [PubMed]

5. Nguipdop-Djomo, P.; Heldal, E.; Rodrigues, L.C.; Abubakar, I.; Mangtani, P. Duration of BCG protection against tuberculosis and change in effectiveness with time since vaccination in Norway: A retrospective population-based cohort study. The Lancet Infect. Dis. 2016, 16, 219-226. [CrossRef]

6. Roth, A.; Gustafson, P.; Nhaga, A.; Djana, Q.; Poulsen, A.; Garly, M.L.; Jensen, H.; Sodemann, M.; Rodriques, A.; Aaby, P. BCG vaccination scar associated with better childhood survival in Guinea-Bissau. Int. J. Epidemiol. 2005, 34, 540-547. [CrossRef] [PubMed]

7. Consonni, D.; Montenegro Agorostos Karagianis, M.M.; Bufardeci, G. Immunisation with BCG in the Maringue district, Sofala province, Mozambique. Tuberc. Res. Treat. 2013, 2013, 312065. [CrossRef] [PubMed]

8. Pang, Y.; Kang, W.; Zhao, A.; Liu, G.; Du, W.; Xu, M.; Wang, G.; Zhao, Y.; Zheng, S. The effect of Bacille Calmette-Guerin vaccination at birth on immune response in China. Vaccine 2015, 33, 209-213. [CrossRef] [PubMed]

9. Scott, S.; Odutola, A.; Mackenzie, G.; Fulford, T.; Afolabi, M.O.; Lowe Jallow, Y.; Jasseh, M.; Jeffries, D.; Dondeh, B.L.; Howie, S.R.; et al. Coverage and timing of children's vaccination: An evaluation of the expanded programme on immunisation in the Gambia. PloS One 2014, 9, e107280. [CrossRef] [PubMed]

10. Animaw, W.; Taye, W.; Merdekios, B.; Tilahun, M.; Ayele, G. Expanded program of immunization coverage and associated factors among children age 12-23 months in Arba Minch town and Zuria district, Southern Ethiopia, 2013. BMC Public Health 2014, 14, 464. [CrossRef] [PubMed]

11. Schoeps, A.; Ouedraogo, N.; Kagone, M.; Sie, A.; Muller, O.; Becher, H. Socio-demographic determinants of timely adherence to BCG, Penta3, Measles, and complete vaccination schedule in Burkina Faso. Vaccine 2013, 32, 96-102. [CrossRef] [PubMed]

12. Le Polain de Waroux, O.; Schellenberg, J.R.; Manzi, F.; Mrisho, M.; Shirima, K.; Mshinda, H.; Alonso, P.; Tanner, M.; Schellenberg, D.M. Timeliness and completeness of vaccination and risk factors for low and late vaccine uptake in young children living in rural Southern Tanzania. Intern. Health 2013, 5, 139-147. [CrossRef] [PubMed]

13. Fadnes, L.T.; Jackson, D.; Engebretsen, I.M.; Zembe, W.; Sanders, D.; Sommerfelt, H.; Tylleskar, T.; Group, P.-E.S. Vaccination coverage and timeliness in three South African areas: A prospective study. BMC Public Health 2011, 11, 404. [CrossRef] [PubMed]

14. Gram, L.; Soremekun, S.; ten Asbroek, A.; Manu, A.; O'Leary, M.; Hill, Z.; Danso, S.; Amenga-Etego, S.; Owusu-Agyei, S.; Kirkwood, B.R. Socio-economic determinants and inequities in coverage and timeliness of early childhood immunization in rural Ghana. Trop. Med. Int. Health 2014, 19, 802-811. [CrossRef] [PubMed]

15. Gidado, S.; Nguku, P.; Biya, O.; Waziri, N.E.; Mohammed, A.; Nsubuga, P.; Akpan, H.; Oyemakinde, A.; Nasidi, A.; Suleman, I.; et al. Determinants of routine immunization coverage in Bungudu, Zamfara state, Northern Nigeria, May 2010. Pan Afr. Med. J. 2014, 18, 9. [CrossRef] [PubMed]

16. Zhao, Y.; Li, M.; Yuan, S. Analysis of transmission and control of tuberculosis in mainland China, 2005-2016, based on the age-structure mathematical model. Int. J. Environ. Res. Public Health 2017, 14, 1192. [CrossRef] [PubMed]

17. Fang, W.; Zhang, L.; Liu, J.; Denning, D.W.; Hagen, F.; Jiang, W.; Hong, N.; Deng, S.; Lei, X.; Deng, D.; et al. Tuberculosis/cryptococcosis co-infection in China between 1965 and 2016. Emerg. Microbes Infect. 2017, 6, e73. [CrossRef] [PubMed]

18. Hu, Y.; Chen, Y.; Guo, J.; Tang, X.; Shen, L. Completeness and timeliness of vaccination and determinants for low and late uptake among young children in Eastern China. Hum. Vaccin. Immunother. 2014, 10, 1408-1415. [CrossRef] [PubMed]

19. Cutts, F.T.; Claquin, P.; Danovaro-Holliday, M.C.; Rhoda, D.A. Monitoring vaccination coverage: Defining the role of surveys. Vaccine 2016, 34, 4103-4109. [CrossRef] [PubMed]

20. Cutts, F.T. The use of the who cluster survey method for evaluating the impact of the expanded programme on immunization on target disease incidence. J. Trop. Med. Hyg. 1988, 91, 231-239. [PubMed]

21. Mbengue, M.A.S.; Mboup, A.; Ly, I.D.; Faye, A.; Camara, F.B.N.; Thiam, M.; Ndiaye, B.P.; Dieye, T.N.; Mboup, S. Vaccination coverage and immunization timeliness among children aged 12-23 months in Senegal: A Kaplan-Meier and cox regression analysis approach. Pan Afr. Med. J. 2017, 27, 8. [PubMed] 
22. Li, Q.; Hu, Y.; Zhong, Y.; Chen, Y.; Tang, X.; Guo, J.; Shen, L. Using the immunization information system to determine vaccination coverage rates among children aged 1-7 years: A report from Zhejiang province, China. Int. J. Environ. Res. Public Health 2014, 11, 2713-2728. [PubMed]

23. Hu, Y.; Li, Q.; Chen, Y. Timeliness of childhood primary immunization and risk factors related with delays: Evidence from the 2014 Zhejiang provincial vaccination coverage survey. Int. J. Environ. Res. Public Health 2017, 14, 1086.

24. Santiago, E.M.; Lawson, E.; Gillenwater, K.; Kalangi, S.; Lescano, A.G.; Du Quella, G.; Cummings, K.; Cabrera, L.; Torres, C.; Gilman, R.H. A prospective study of Bacillus Calmette-Guerin scar formation and tuberculin skin test reactivity in infants in Lima, Peru. Pediatrics 2003, 112, e298. [CrossRef] [PubMed]

25. Timmermann, C.A.; Biering-Sorensen, S.; Aaby, P.; Fisker, A.B.; Monteiro, I.; Rodrigues, A.; Benn, C.S.; Ravn, H. Tuberculin reaction and BCG scar: Association with infant mortality. Trop. Med. Int. Health 2015, 20, 1733-1744. [CrossRef] [PubMed]

26. Roth, A.; Sodemann, M.; Jensen, H.; Poulsen, A.; Gustafson, P.; Weise, C.; Gomes, J.; Djana, Q.; Jakobsen, M.; Garly, M.L.; et al. Tuberculin reaction, BCG scar, and lower female mortality. Epidemiology 2006, 17, 562-568. [CrossRef] [PubMed]

27. Garly, M.L.; Martins, C.L.; Bale, C.; Balde, M.A.; Hedegaard, K.L.; Gustafson, P.; Lisse, I.M.; Whittle, H.C.; Aaby, P. BCG scar and positive tuberculin reaction associated with reduced child mortality in West Africa. A non-specific beneficial effect of BCG? Vaccine 2003, 21, 2782-2790. [CrossRef]

28. Rammohan, A.; Awofeso, N.; Fernandez, R.C. Paternal education status significantly influences infants' measles vaccination uptake, independent of maternal education status. BMC Public Health 2012, 12, 336. [CrossRef] [PubMed]

29. Nankabirwa, V.; Tylleskar, T.; Tumwine, J.K.; Sommerfelt, H.; Promise-EBF Study, G. Maternal education is associated with vaccination status of infants less than 6 months in Eastern Uganda: A cohort study. BMC Pediatr. 2010, 10, 92. [CrossRef] [PubMed]

30. Jean, S., 3rd; Elshafei, M.; Buttenheim, A. Social determinants of community-level human papillomavirus vaccination coverage in a school-based vaccination programme. Sex. Transm. Infect. 2018, 94, 248-253. [CrossRef] [PubMed]

31. Onsomu, E.O.; Abuya, B.A.; Okech, I.N.; Moore, D.; Collins-McNeil, J. Maternal education and immunization status among children in Kenya. Matern. Child. Health J. 2015, 19, 1724-1733. [CrossRef] [PubMed]

32. Saitoh, A.; Saitoh, A.; Sato, I.; Shinozaki, T.; Nagata, S. Current practices and needs regarding perinatal childhood immunization education for Japanese mothers. Vaccine 2015, 33, 6128-6133. [CrossRef] [PubMed]

33. Shahnazi, H.; Sabooteh, S.; Sharifirad, G.; Mirkarimi, K.; Hassanzadeh, A. The impact of education intervention on the health belief model constructs regarding anxiety of nulliparous pregnant women. J. Educ. Health Promot. 2015, 4, 27. [PubMed]

34. Abadura, S.A.; Lerebo, W.T.; Kulkarni, U.; Mekonnen, Z.A. Individual and community level determinants of childhood full immunization in Ethiopia: A multilevel analysis. BMC Public Health 2015, 15, 972. [CrossRef] [PubMed]

35. Ahanhanzo, C.D.; Huang, X.X.; Le Gargasson, J.B.; Sossou, J.; Nyonator, F.; Colombini, A.; Gessner, B.D. Determinants of routine immunization costing in Benin and Ghana in 2011. Vaccine 2015, 33 (Suppl. 1), A66-A71. [CrossRef] [PubMed]

36. Al-Mendalawi, M.D. Immunization coverage and its determinants among children 12-23 months of age in Aden, Yemen. Saudi Med. J. 2011, 32, 318. [PubMed]

37. Nath, L.; Kaur, P.; Tripathi, S. Evaluation of the universal immunization program and challenges in coverage of migrant children in Haridwar, Uttarakhand, India. Indian J. Community Med. 2015, 40, 239-245. [CrossRef] [PubMed]

38. Hu, Y.; Luo, S.; Tang, X.; Lou, L.; Chen, Y.; Guo, J. Comparative assessment of immunization coverage of migrant children between national immunization program vaccines and non-national immunization program vaccines in East China. Hum. Vaccin. Immunother. 2015, 11, 761-768. [CrossRef] [PubMed] 
39. Liu, R.; Li, Y.; Wangen, K.R.; Maitland, E.; Nicholas, S.; Wang, J. Analysis of hepatitis B vaccination behavior and vaccination willingness among migrant workers from rural China based on protection motivation theory. Hum. Vaccin. Immunother. 2016, 12, 1-9. [CrossRef] [PubMed]

40. Burgess, D.C.; Burgess, M.A.; Leask, J. The MMR vaccination and autism controversy in United Kingdom 1998-2005: Inevitable community outrage or a failure of risk communication? Vaccine 2006, 24, 3921-3928. [CrossRef] [PubMed]

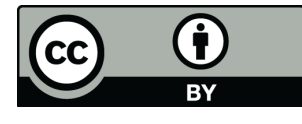

(C) 2018 by the authors. Licensee MDPI, Basel, Switzerland. This article is an open access article distributed under the terms and conditions of the Creative Commons Attribution (CC BY) license (http://creativecommons.org/licenses/by/4.0/). 